\title{
A validity-driven approach to the understanding of the personal and societal burden of low back pain: development of a conceptual and measurement model
}

Rachelle Buchbinder ${ }^{1,2^{*} \dagger}$, Roy Batterham ${ }^{3 \dagger}$, Gerald Elsworth ${ }^{3}$, Clermont E Dionne ${ }^{4,5}$, Emma Irvin ${ }^{6}$ and Richard H Osborne ${ }^{3}$

\begin{abstract}
Introduction: While the importance and magnitude of the burden of low back pain upon the individual is well recognized, a systematic understanding of the impact of the condition on individuals is currently hampered by the lack of an organized understanding of what aspects of a person's life are affected and the lack of comprehensive measures for these effects. The aim of the present study was to develop a conceptual and measurement model of the overall burden of low back pain from the individual's perspective using a validity-driven approach.

Methods: To define the breadth of low back pain burden we conducted three concept-mapping workshops to generate an item pool. Two face-to-face workshops (Australia) were conducted with people with low back pain and clinicians and policy-makers, respectively. A third workshop (USA) was held with international multidisciplinary experts. Multidimensional scaling, cluster analysis, participant input and thematic analyses organized participants' ideas into clusters of ideas that then informed the conceptual model.
\end{abstract}

Results: One hundred and ninety-nine statements were generated. Considerable overlap was observed between groups, and four major clusters were observed - Psychosocial, Physical, Treatment and Employment - each with between two and six subclusters. Content analysis revealed that elements of the Psychosocial cluster were sufficiently distinct to be split into Psychological and Social, and a further cluster of elements termed Positive Effects also emerged. Finally, a hypothesized structure was proposed with six domains and 16 subdomains. New domains not previously considered in the back pain field emerged for psychometric verification: loss of independence, worry about the future, and negative or discriminatory actions by others.

Conclusions: Using a grounded approach, an explicit a priori and testable model of the overall burden of low back pain has been proposed that captures the full breadth of the burden experienced by patients and observed by experts.

\section{Introduction}

Low back pain affects 80 to $85 \%$ of people at some stage in their life $[1,2]$ and is a major source of morbidity throughout the world [3]. This condition is one of the most common causes of disability, lost work-days and visits to primary care practitioners in high-income

\footnotetext{
* Correspondence: rachelle.buchbinder@monash.edu

+ Contributed equally

'Monash Department of Clinical Epidemiology, Cabrini Hospital, 183 Wattletree Road, Malvern, Victoria 3144, Australia

Full list of author information is available at the end of the article
}

countries [4-8]. Not only does low back pain have physical, psychological, social and economic consequences on the individual, its impact upon families, communities, industries and governments is enormous $[4,9,10]$. Recent epidemiological studies indicate that severe low back pain increases into old age [9] and may be increasing in prevalence in adolescence $[11,12]$, demonstrating a growing public health concern [13].

While the importance and magnitude of the burden of low back pain upon the individual is well recognized, a

\section{C) Biomed Central}


systematic understanding of the impact of the condition on individuals is currently hampered by the lack of an organized understanding of what aspects of a person's life are affected, and also by the lack of comprehensive measures of these effects. The burden of a disease is commonly defined in terms of mortality, morbidity (incidence and prevalence), cost and, more recently, disability and quality of life. While these are recognized as components of disease burden, none alone are sufficient for quantifying the overall burden of low back pain from the perspective of the individuals affected.

To date the measurement of the burden of low back pain has been based on indicators such as those mentioned above rather than on empirical reflections of the way in which back pain affects the lives of individuals with the condition and those associated with them. In part this relates to a general problem in measurement development, where measures are often based on theory or historically convenient indicators and tools. Measures developed using this process rarely provide a complete view of an issue and they are usually incomplete in unknown ways. The psychometric literature refers to the failure to cover all aspects of an issue as 'construct under-representation' [14], and highlight this as a serious threat to the validity of any measurement tool $[14,15]$.

The greater danger is that measures based upon incomplete coverage of a problem may then become widely used, which in turn affects the care provided and the outcomes that are valued (and funded). In relation to back pain, there is a mismatch between traditional approaches to measurement of impact, which have little focus on social issues, and evidence showing that social issues and complex interactions between social, psychological, physical and functional issues are the norm [16,17].

The present paper has two equal and interacting aims. First, the article aims to develop a conceptual framework that can be generalized cross-culturally, to estimate the various impacts and overall burden of low back pain from the perspective of individuals with this condition and to explore the pathways by which the individual burden of low back pain becomes a burden for society. This conceptual model will then guide the development of the new measure.

The second aim of the paper is to demonstrate, using the example of low back pain, a process for concept definition and instrument development that is consciously and deliberately directed by modern approaches to validity, from the initial stages of conceptualization through all stages of application of the resultant tool.

In trying to capture these interacting aims, we have adopted the term validity-driven to describe a process that includes: grounded approaches to a concept definition that includes consultation with a broad range of stakeholders and deliberately eschews prevailing theories until later in the development process; stakeholder participation in the organization of ideas into groups that form the basis for hypothesizing scales to be included in the measurement tool; the development of $a$ priori hypotheses about the way in which items co-vary and can be used to form measurement scales; recognition that construct validation is an ongoing process, and that an instrument is never validated but that each interpretation of the scores needs to be validated; and the specification of a program of research to support the valid application of the tool in relation to an increasing range of interpretations (uses).

In keeping with this process, the end point of the present paper is the detailing of the hypothesized measurement model of the overall burden of back pain from the perspective of individuals with this condition and the description of a proposed program of validation research. The approaches described in this paper have evolved in the instrument development and application work of members of the research team over more than a decade [18-24]. However, this is the first time that the whole process was formalized in advance, as a comprehensive approach to instrument development.

\section{Materials and methods}

\section{Study design and participants}

A grounded approach to conceptualization and the identification of draft items maximizes the likelihood that the resultant tool will fully cover the construct; in this case, the burden of low back pain. Our process for grounded conceptualization included three concept mapping groups that utilized processes modified from the methods developed by Trochim [25]. Concept mapping is a formal group process tool for identifying and organizing ideas on a topic of interest. The steps include development of a seeding statement, generation of statements (brainstorming), sorting of the statements, generation of a concept map and revision of the concept map.

The Cabrini Human Research Ethics Committee approved the study (No. 13-02-03-09) and all patients who participated in the study provided written informed consent.

\section{Naming groups of items that are (or are hypothesized to be) related}

There are many options for naming groups of items, including clusters, domains, factors, scales and dimensions. We chose not to use the term 'dimensions' because it has a specific meaning when using multidimensional scaling (MDS), which relates to the number of spatial dimensions in which the MDS software seeks 
to fit the distances between items. We also chose not to use the term 'factors' because it relates to a specific type of statistical technique - factor analysis.

We use the term 'clusters' when we refer to the outcomes of concept mapping and the term 'domains' when we refer to a refined, hypothesized structure for a proposed instrument. These domains are referred to technically as latent variables during psychometric analysis using structural equation modeling. We use the term 'scales' after the psychometric properties of the instrument have been established.

We consider that the matching between clusters, domains (latent variables) and scales is one of the critical elements in demonstrating construct validity of the final tool. We also use the term 'statements' to refer to the ideas generated by participants in the concept mapping groups, and use the term 'items' when we have begun to redraft these statements into a form that is suitable for a questionnaire.

\section{Concept mapping workshops with patients and professionals}

We conducted two face-to-face concept mapping workshops in Melbourne, Australia. We sought patients from typical clinical and community settings, with the intention of capturing a broad range of experiences. One workshop included patients with low back pain of varying duration and severity recruited from a communitybased rheumatology private practice as well as individuals who had identified themselves as having back pain from a research database of people with chronic conditions who have participated in chronic disease self-management education programs across Australia, held at the Centre for Rheumatic Diseases, University of Melbourne $(n=8)$.

The other workshop included a diverse range of clinicians and health policy-makers from government, WorkSafe (a government-operated workers' compensation insurance scheme in Victoria, Australia) and private health insurers, identified through professional networks and snowball recruitment $(n=10)$. We separated the patient and professional groups in order to facilitate frank discussion, and broad and rapid brainstorming.

To maximize the richness and depth of the data obtained, we used a nominal group process that is a method for obtaining the most comprehensive possible range of ideas from individuals on a topic of interest [26]. Usual practice in qualitative data collection is to sample to saturation, which is the point at which no new ideas are emerging. The concept mapping process goes to great lengths to be as exhaustive as possible within each group, and therefore saturation is often reached after a small number of groups.
A carefully crafted seeding statement was presented to individuals in each group, who were then asked to work alone for 5 minutes to generate ideas in response to the statement. The seeding statement for patients was: 'Thinking as broadly as you can, generate statements about how low back pain affects your life (considering both yourself and those around you'). For the health professional group, the seeding statement was slightly different: 'Thinking as broadly as you can, generate statements about how low back pain affects the life of people with the condition and the community'. Participants were asked to write down their responses according to the following rules: one idea per statement, use bullet points, make the statements brief, and work alone. The nominal group technique uses a facilitator who then asks that the ideas be presented to the group in an egalitarian manner, whereby each participant in turn presents one item on their list, starting with the first, until all items have been presented. Participants were discouraged from passing judgments about the statements but were encouraged to seek clarification of the nature or content of the statement if necessary. The critical advantage of this approach is that the perspective of individuals is collected in a manner that is not influenced or biased by the researcher nor influenced by other, and at times dominant, group members.

Once all statements had been presented, participants were asked to sort the statements into conceptually similar groups according to any system that made sense to them. For this step, they were asked to work alone. MDS and cluster analysis were then used to process participants' input and generate two-dimensional maps of key concepts related to low back pain impact and the interrelationships among these clusters.

Participants were asked to independently consider and label each group of statements and to check that each of the statements fit within that group. If a statement or statements were not considered to fit within the group, participants were asked to nominate the appropriate grouping. They were also asked to consider whether any of the groups should be joined. After this had been completed on an individual basis, we again used a nominal group approach to organize the final groupings, their labels and the included statements. We also checked for any missing domains/concepts.

\section{Concept mapping with international experts}

A similar concept mapping exercise was conducted via email and through a face-to-face workshop at the 10th International Forum for Primary Care Research on Low Back Pain held in Boston in 2009. The expertise of the expert international group was broad and included primary care, rheumatology, occupational health, 
physiotherapy, chiropractics, epidemiology, public health and health policy.

Prior to the Forum, an email was sent to all participants who had been allocated to the workshop $(n=31)$ asking them to generate statements in response to a similar seeding statement: 'Thinking as broadly as you can, generate statements about ... how low back pain affects the life of people with the condition and those around them'. Forty-five percent (14/31) of participants responded to this task.

The statements from the patient group, from the clinician/health policy group and from the Forum workshop participants were then combined and redundancies were removed. This final set of statements were then sent to Forum participants in a second email requesting that they sort the statements into conceptually similar groups according to any system that made sense to them. They were also asked to rank each of the statements in order of importance. Fifty-eight percent (18/31) completed this task.

The same process of multidimensional scaling and cluster analysis was used to process participants' input and generate two-dimensional maps of key clusters of low back pain impact and the interrelationships among these clusters.

At the Forum we presented the results of the patient and clinician/health policy-maker workshops and the final concept map that was generated by the Low Back Pain Forum workshop participants. Participants were asked to independently consider and label each group of statements and to check that each of the statements fit within that group. If a statement or statements were not considered to fit within the group, participants were asked to nominate the appropriate grouping. They were also asked to consider whether any of the groups should be joined. After this had been completed on an individual basis, the group worked together to organize the final groupings, their labels and the included statements. We also checked for any missing domains or concepts.

\section{Integration of the three concept maps}

At this point we had three concept maps: two from the initial groups and one from the international expert group. The process of integrating the three maps included a number of steps. In addition to the twodimensional MDS that underlies the concept maps, we undertook three-dimensional and four-dimensional MDS using the Clustan software [27] and repeated the cluster analysis on the outputs of these analyses. Sometimes a three-dimensional or four-dimensional MDS can more accurately capture the similarities between statements and leads to cleaner (more self-evidently homogeneous) clusters. The output of the MDS and cluster analysis is viewed as a tree diagram; a diagram that allows all cluster solutions from a single cluster to a number that equals the number of items to be examined. This diagram allows us to examine the division of items each time a cluster is split into two smaller clusters to determine whether this split has substantive meaning. Through this process we looked to determine the smallest number of clusters (most general concepts) that made sense, the largest number of clusters (most refined concepts) that made sense, and the items that are considered most typical of each refined concept.

At the level of the most general concepts, the results from different concept mapping groups tend to be similar. This means that the results can be combined at this level and the results from the different concept mapping groups provide different details under these high-level concepts. These results for each group analysis are displayed as mind maps (Mindjet Mind Manager software, 2010, MindJet Ltdr, Sydney, New South Wales, Australia). The mind maps are then combined so that the common general concepts form the first level of detail and the branches represent each substantively meaningful split identified through examination of the tree diagrams.

Throughout this process the researchers attempted to use the cluster names assigned by the original group participants. The mind map aims to provide a clear hierarchical overview of the burden of low back pain as seen by the participants. This hierarchical representation does not, however, show the richness of the relationships between the clusters as well as the original maps. For this reason, the integrated mind map needs to always be considered in conjunction with the original maps.

\section{Refinement of the structural model}

The next step in refining the structural model was to check the proposed domains against the original item pool. The researchers classified every statement produced by the three concept mapping groups according to the proposed domains. In performing this classification we were looking for: items that cannot be classified - these may indicate the need for additional domains; items that seem to relate to more than one domain these may be ambiguous items or may indicate a relationship between the hypothesized domains; domains that still seemed to contain multiple concepts and may need to be split; and match between domain names and the item content - a poor match may require renaming the hypothesized domain.

\section{Results}

In response to the seeding statements, the three groups produced 305 statements: 47 from the patients, 61 from the stakeholders and 197 from the international expert 
Table 1 Number of participants contributing to concept mapping and the number of statements produced

\begin{tabular}{lll}
\hline & Number of participants & Number of statements \\
\hline Low back pain patient group & 8 & 47 \\
Stakeholders & 10 & 61 \\
Low Back Pain Forum workshop participants & 14 generated statements & 197 \\
& 18 completed sorting and rating of final set of statements & $91^{\mathrm{a}}$ \\
\hline
\end{tabular}

${ }^{a}$ The final set of 91 statements was derived by combining statements from all three groups omitting redundancies.

panel (Table 1). Removing duplicates, the final set comprised 91 statements.

Figure 1 shows the concept map produced by the international expert panel. Each of the bounded shapes represents a cluster of statements. The large number is the cluster number designated by the software (that is, cluster 1 , cluster 2 , and so forth). The small numbers within each cluster represent the statements produced by the group in the nominal group phase (that is, each statement is given a number as it is entered into the program). In interpreting a concept map, it is usually best to work systematically around the edge of the map and then look at the central clusters. The items circled by dashed lines were considered to relate strongly to other items; this is inevitable when there are many ways of thinking about a concept.

Some of the most notable features of the map shown in Figure 1 are: the large number of statements related to the interaction between the reactions of others and the person's psychological state (seen in the top righthand corner); the variety of statements related to the effort of living (down the right-hand side), which range from having to think about and plan daily activities and the physical weariness of many activities to having to make enduring changes in lifestyle; the burden related to peoples' interactions with societal institutions, including workplaces and treatment services (left-hand side); and the concepts that have both individual and health service aspects, such as effects of treatment and health states (central clusters). The maps produced by the other groups had a similar range of concepts and a similar emphasis on issues associated with the reactions of others and the effort of daily living.

The next step involved the examination of the tree diagrams related to each of the concept maps to identify the minimum number of clusters that made sense, the maximum number that made sense, and representative statements - each of which was represented as a mind map. The result of this process is presented in Table 2, which in turn was used to hypothesize a set of major domains and subdomains and the structural model presented in Figure 2.

As shown in Table 2 we identified four clusters (Psychosocial, Physical, Treatment and Employment), and each cluster included a variable number of subclusters. For example, within the Psychosocial cluster there were six subclusters including loss, negative affect, worry and

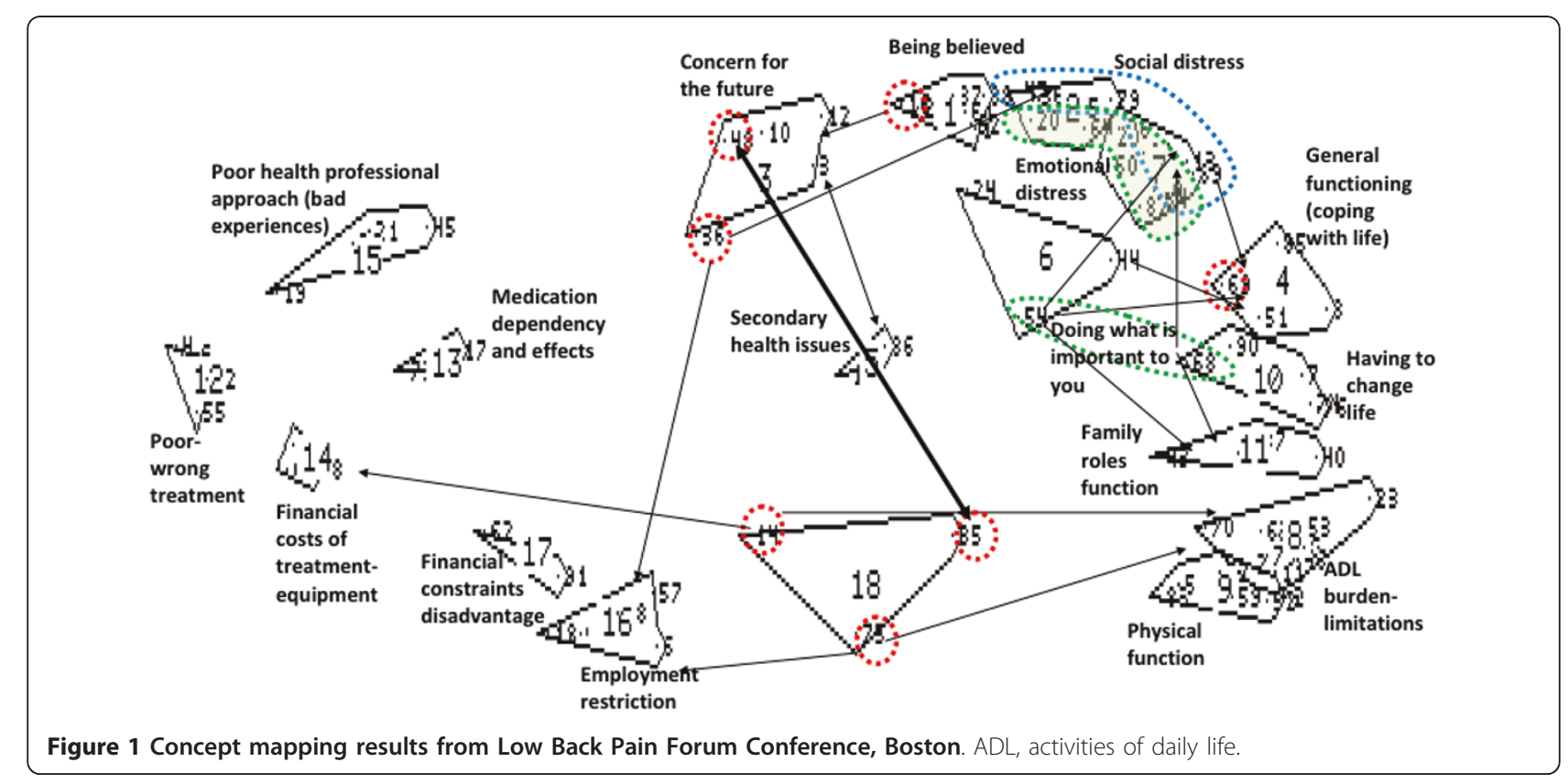


Table 2 Clusters, subclusters and representative statements

\begin{tabular}{|c|c|}
\hline Clusters and subclusters & Representative statements \\
\hline \multicolumn{2}{|l|}{ Psychosocial } \\
\hline \multicolumn{2}{|l|}{ Loss } \\
\hline Loss of expectations & Limitations on fulfillment of goals in life \\
\hline Loss of enjoyment & Loss of enjoyment in life \\
\hline \multirow[t]{2}{*}{ Loss of self-confidence } & Low self-esteem, especially from loss of roles \\
\hline & Feel helpless when people stop you doing things \\
\hline Negative affect & Irritation, anger and frustration \\
\hline \multirow[t]{2}{*}{ Worry and negative beliefs about the future } & Worry about the future \\
\hline & Fear that severe back pain will occur again \\
\hline \multicolumn{2}{|l|}{ Global malaise } \\
\hline \multirow[t]{2}{*}{ Secondary health effects } & Difficult to address other health issues \\
\hline & May lead to weight gain \\
\hline \multirow[t]{3}{*}{ Effort of life/daily grind } & Tiredness \\
\hline & Makes you feel old \\
\hline & Loss of motivation in life \\
\hline Executive challenge & Always having to think about what you can and cannot do \\
\hline \multicolumn{2}{|l|}{ Domestic psychosocial challenges } \\
\hline \multirow[t]{2}{*}{ Loss of family and intimate involvement } & Left out of family activities \\
\hline & Difficulty caring for others \\
\hline Loss of independence & Need to ask for help to do things \\
\hline \multicolumn{2}{|l|}{ Negative reactions ${ }^{a}$} \\
\hline \multirow[t]{2}{*}{ Challenged integrity/feeling believed } & May be seen as a malingerer \\
\hline & Wrongly considered lazy by others \\
\hline \multirow[t]{2}{*}{ Self-worth degraded by how you feel others see you } & Always trying to hide pain from family so they do not worry \\
\hline & Feel like a burden on workmates \\
\hline \multirow[t]{2}{*}{ Negative/discriminatory actions by others } & Bullied by others \\
\hline & May lose friends \\
\hline \multicolumn{2}{|l|}{ Physical } \\
\hline \multirow[t]{2}{*}{ Functioning outside the home } & Makes it hard to travel \\
\hline & Leisure activities are limited \\
\hline \multirow[t]{3}{*}{ Specific physical limitations } & Daily living is hard including basic self-care \\
\hline & Difficulty lifting things \\
\hline & Hard to sit \\
\hline \multirow[t]{2}{*}{ General physical impact } & More and more physically unfit \\
\hline & Fall easily \\
\hline \multicolumn{2}{|l|}{ Treatment } \\
\hline \multicolumn{2}{|l|}{ Treatment services } \\
\hline \multirow[t]{2}{*}{ Frustration of treatment (quality) } & Waste time and money on dubious treatments and practitioners \\
\hline & Unnecessary surgery and the problems this causes \\
\hline \multirow[t]{2}{*}{ Frustration with healthcare providers } & Doctors not understanding there is anything wrong with you \\
\hline & Back pain can make you distrust the medical profession \\
\hline \multicolumn{2}{|l|}{ Condition burden } \\
\hline Impact on others ${ }^{\mathrm{b}}$ & Need help from carers \\
\hline Medication & Dependent on more and more medication \\
\hline & Side-effects \\
\hline Financial costs/expenses & Costs of treatment and equipment (necessary and unnecessary) \\
\hline Employment & \\
\hline Challenges when out of work & Difficult to get back to paid employment \\
\hline & Reduced employment options, now and for the future \\
\hline Challenges when working ${ }^{c}$ & Many limitations on what tasks can be done \\
\hline Effects of employment challenges & Difficult to get health insurance \\
\hline & Reduced income resulting in poverty \\
\hline
\end{tabular}




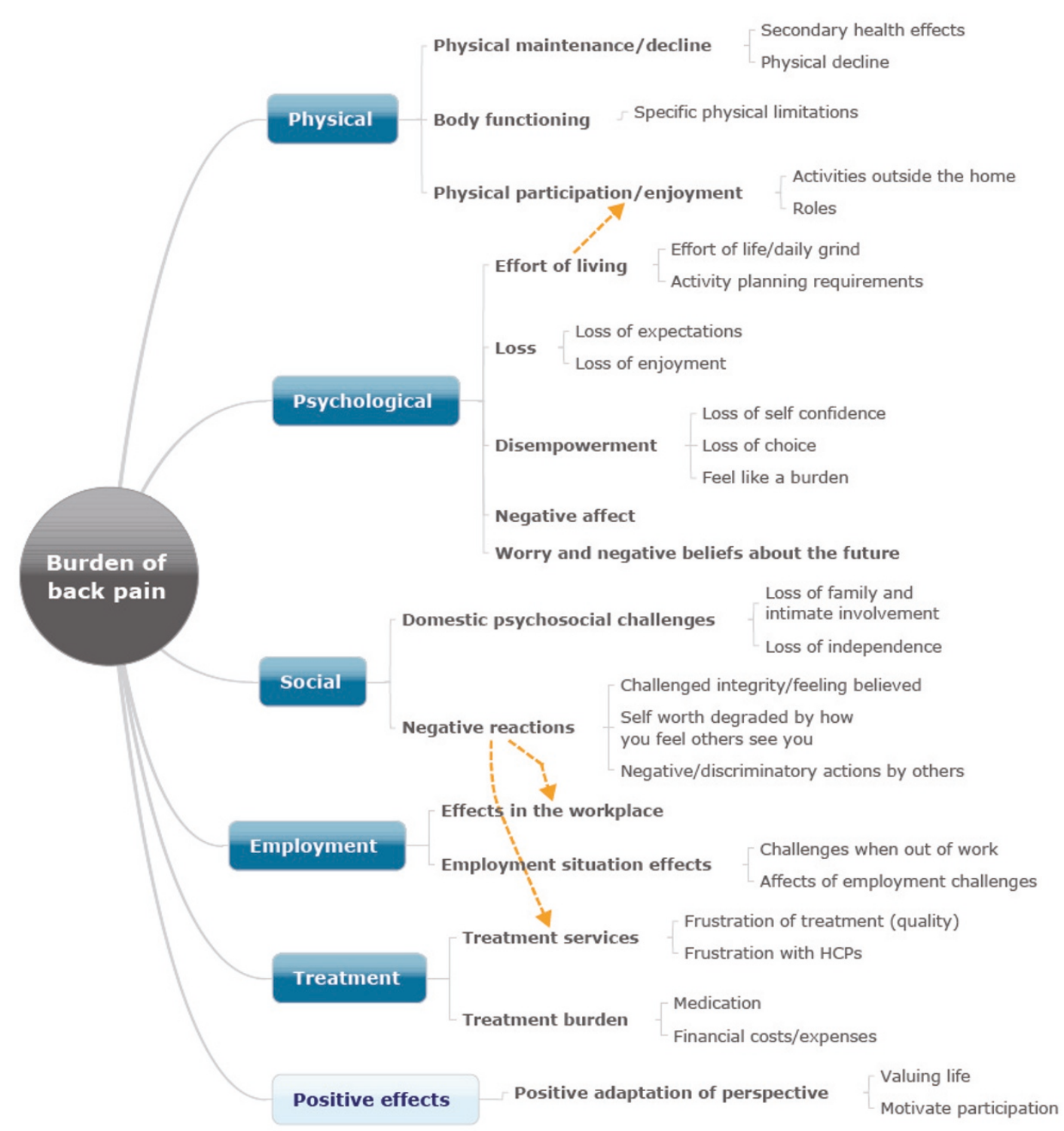

Figure 2 Hierarchical model of low back pain burden (integrated from all concept maps). HCP, healthcare practitioner.

negative beliefs about the future, global malaise, domestic psychosocial challenges, and negative reactions.

Figure 3 refines the hierarchical model developed from the mind map (Figure 2), to further hypothesize latent variables that are represented by a number of candidate items (derived from the concept mapping groups). The circles in Figure 3 each represent a hypothesized latent variable. In this model we hypothesize that there are six major domains, some of which have subdomains (up to five) and some of which do not. Given item content, we also hypothesize two further independent domains: Choice or control, which will be related to elements within the physical and psychological domains; and Discrimination, which will be related to elements within the social and treatment domains.

\section{Discussion}

Validity-driven instrument development

Our approach to construct definition and instrument development is based on the tenet that construct validity needs to be the primary concern of all instrument development activities and of all proposed applications of instruments. This is consistent with the descriptions provided by Pedhazur and colleagues [28], and the Standards for Educational and Psychological Testing developed jointly by the American Educational Research Association, the American Psychological Association 


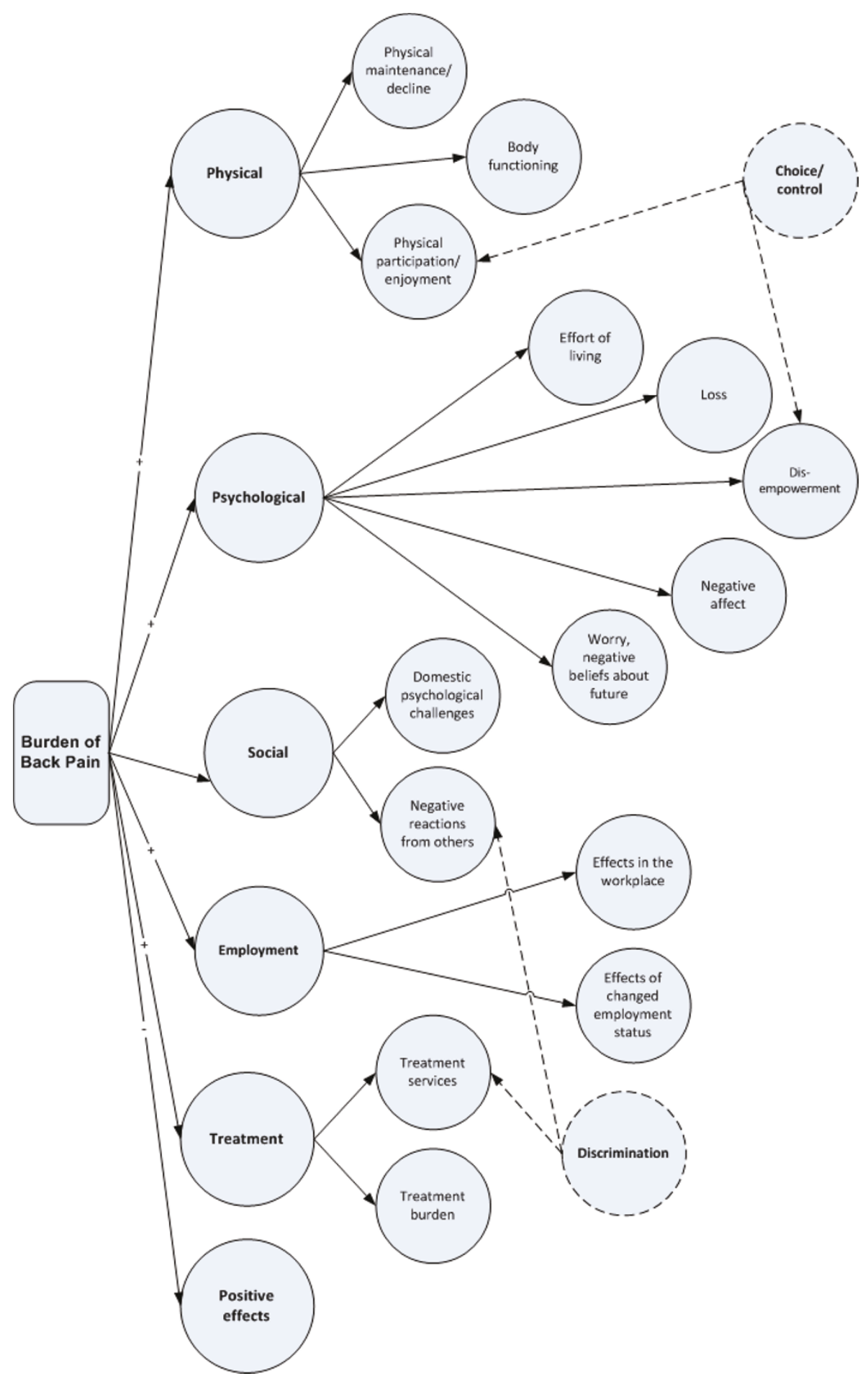

Figure 3 Hypothesized, a priori measurement model to be tested with construction and validation samples

and the (American) National Council on Measurement in Education [29,30]. The Standards describe validation as an ongoing process that commences with the conceptualization and continues each time someone proposes an additional interpretation or application of the tool [29].

While it is common practice in health research to refer to a tool as either validated or unvalidated, it is 
not tools but only their interpretations and applications that are validated. To maximize the likelihood of producing valid data in relation to a range of possible interpretations and applications of a tool, there are development processes that seek to protect the instrument against two categories of error; measuring less than the proposed construct (construct underrepresentation) or measuring more (construct irrelevant variance) [29]. Protection against the first type of error requires rigor in the processes of conceptualization and definition and the identification of a range of indicators. Protection against the second type of error requires rigor in psychometric analysis. We believe that three disciplines help achieve this necessary rigor: the use of grounded approaches for construct definition; the development of a priori structural hypotheses (that define relevant versus irrelevant variance); and the development of a priori, relational hypotheses as a basis for future construct validation.

The Standards contain 24 standards related to validity of a measure, but the first four of these specifically relate to the linkage between validity and possible interpretations (Table 3). It is clear that the authors of the Standards place a significant onus of responsibility on the developers of instruments to clarify the interpretations that are supported by available evidence at any point in time.

An important initial step in scale development, and the final step in development of the hypothesized model, involves writing (hypothesized) descriptors about characteristics of people with a high score and people with a low score on scales related to each hypothesized domain. This exercise helps to clarify whether the domain can be represented as a scale or whether it is simply a checklist of possible characteristics, the desired range of item difficulty, and possible relationships between scale scores and other variables (other scales, demographic and clinical variables, outcomes of interventions). This final point is an important and often neglected step in preparing for construct validation by developing a broad range of $a$ priori hypotheses about the behavior of the scales in relation to other variables (the so-called nomothetic web) $[28,31]$.
In considering the ongoing process of validation once the instrument has been developed, it is necessary to specify the interpretations and applications that we are seeking to validly and reliably achieve. These interpretations and applications are presented in Table 4, together with some of the evidence - or the processes to obtain the evidence - that is required to support validity of each type of interpretation/application. Table 4 shows that the expansion of valid interpretations and applications occurs in a number of stages that build upon each other. The first two stages are integral to the process of psychometric development through the application of draft tools to a construction and validation sample (see below). Evidence in relation to the second two proposed applications accrues through use of the tool, while the step from interpretation of data at the group level to interpretation at the individual level usually requires additional technical analysis as well as a body of evidence about the meaning and behavior of each scale acquired through widespread use with groups. There are also steps that can be taken during the psychometric development phase to increase the likelihood that the tool will be usable with individuals. These steps relate to ensuring that the scales have certain properties in relation to the range of difficulty that the items cover and the extent to which they can give scores spread evenly across this range. While the meaning of difficulty is clear in academic tests in this situation, a difficult item would be one where few people give the most positive possible response. There are also different reliability requirements related to each level of use, with individual applications having the most stringent requirements.

\section{Implications for the measurement of the burden of low back pain}

One of the primary reasons for conducting this research was the observation that existing instruments inadequately capture the range of impacts of low back pain that are commonly reported by people with low back pain and the clinicians that work with them. This project has produced a conceptual framework that includes many concepts not included in the tools most commonly used to assess needs and/or outcomes for people with low back pain.

\section{Table 3 Standards relating validity to interpretations}

$\begin{array}{ll}\begin{array}{l}\text { Standard } \\ 1.1\end{array} & \begin{array}{l}\text { A rationale should be presented for each recommended interpretation and use of test scores, together with a comprehensive summary } \\ \text { of the evidence and theory bearing on the intended use or interpretation }\end{array} \\ \begin{array}{l}\text { Standard } \\ 1.2\end{array} & \begin{array}{l}\text { The test developer should set forth clearly how test scores are intended to be interpreted and used. The populations(s) for which a test } \\ \text { is appropriate should be clearly delimited and the construct that the test is intended to assess should be clearly described }\end{array} \\ \begin{array}{ll}\text { Standard } & \text { If validity for some common or likely interpretation has not been investigated, or if the interpretation is not consistent with the } \\ 1.3 & \text { available evidence, that fact should be made clear and potential users should be cautioned against making unsupported interpretations } \\ \text { Standard } & \begin{array}{l}\text { If a test is to be used in a way that has not been validated, it is incumbent on the user to justify the new use, collecting new evidence } \\ 1.4\end{array}\end{array}\end{array}$




\section{Table 4 Proposed interpretations/applications and evidence required to support the measure's validity for low back} pain burden

\begin{tabular}{ll}
\hline Proposed interpretation/application & Evidence of validity or activities to obtain this evidence
\end{tabular}

Interpretations/applications applied to groups - supported through initial development processes

Describe the burden of low back pain on a set of scales that reflects the full Thorough, grounded identification of the range of issues that range of the experience of people with low back pain contribute to low back pain burden

Iterative process of organizing these into domains and potential scales

Comparison with interview data at a number of stages of development

Quantify variations in the effects of low back pain across a broad range of sufferers on a range of scales
Cluster analysis to identify score profiles and qualitative confirmation of these

Tests of structural invariance across groups

\section{Interpretations/applications applied to groups - supported through subsequent applications of the tool ${ }^{\mathrm{a}}$}

Describe the relative importance of different domains of low back pain burden in comparing one population with another (for example, needs identification)

Accumulated evidence about what is a high average score and what is a low average score for each scale ${ }^{b}$

Establishment of whole of population norms and subgroup norms Tests of structural invariance

Validly assess changes in low back pain burden in a group over time or as a result of interventions

Application for a range of evaluation purposes including comparison with other subjective and objective indicators of change

Development of estimates of meaningful change

Interpretations/applications applied to individuals

Assess the relative needs of an individual with low back pain across a range of domains

Measure changes in individuals over time or in response to interventions
Attention to item scaling properties during psychometric development

Comparison with other subjective and objective indicators of status

Comparison with other subjective and objective indicators of change

Development of estimates of meaningful change

${ }^{\mathrm{a}}$ Two further possible applications are the development of an overall score to compare the total burden of one population group with another, and also the attachment of utilities to scores to enable comparisons with other conditions. At this stage we do not propose to pursue either of these applications. ${ }^{b}$ It is important to note that we do not assume the scales all scale equally or that an average score of 3.5 on one scale will necessarily indicate a greater problem than a score of 4 on another scale. These relative weightings are necessarily dependent on the values of individuals or on some estimate of the average values of groups and populations.

At one end of the spectrum, because low back pain has until recently been thought mainly a work-related problem, outcome measures have often been limited to occupational aspects of burden: most of all, measures of absence from work, and the consequent financial costs. Such measures only capture part of the burden of low back pain.

At the other end of the spectrum, Deyo and colleagues proposed a core set of six indicators for routine clinical use that included pain symptoms, function, well-being, disability, social role and satisfaction with care [32]. Another core set of measures proposed for evaluating the effectiveness of treatment in clinical trials and routine care was proposed by Bombardier [33]. Recognizing the importance of the patient's perspective, she proposed the following five domains: back-specific function, generic health status, pain, work disability, and patient satisfaction [33]. Similar to these proposals, the Initiative on Methods, Measurement, and Pain Assessment in Clinical Trials group recommended a core set of six outcome domains be considered in chronic pain clinical trials: pain, physical functioning, emotional functioning, participant ratings of global improvement and satisfaction with treatment, symptoms and adverse events, and participant disposition [34].

More recently, Kopec and colleagues proposed a webbased computerized adaptive test (CAT-5D-QOL) to measure five domains of health-related quality of life (Daily Activities, Walking, Handling Objects, Pain or Discomfort, and Feelings) for patients with back pain based upon item banks developed for these domains relevant to arthritis [35]. Many measures have been developed to specifically quantify the limitations that low back pain places upon functional status. For example, in a 2004 systematic review Grotle and colleagues identified a total of 36 back-specific questionnaires [36]. The authors classified the content of the questionnaires based upon the World Health Organization's International Classification of Functioning, Disability and Health (ICF); they found that while most of the questionnaires had a focus on activity limitations, there was a wide variation in their underlying constructs and content. Many questionnaires also included constructs of pain and symptoms, sleep disturbances, psychological dysfunction, physical impairment and social functions. 
The brief and comprehensive ICF core sets for low back pain, based upon the ICF framework, are further attempts to develop a standardized set of indicators to encompass the key functional problems of patients with low back pain envisaged to be used for a variety of purposes including clinical studies and multidisciplinary assessment in clinical care [37]. These were formed by consensus among a group of international clinical experts comprising physicians, occupational and physical therapists, who integrated evidence from a Delphi exercise to identify the most relevant ICF categories in patients with chronic health conditions including back pain [38], a systematic review to identify the concepts contained in outcome measures in clinical trials of musculoskeletal disorders and chronic widespread pain [39], and a study in a convenience sample of people undergoing rehabilitation for one of several chronic conditions including low back pain who were administered the ICF checklist [40]. The comprehensive and brief ICF core sets include 78 and 35 categories, respectively, which cover not only aspects related to pain but also a wide spectrum of activities, social and environmental factors that affect functioning. In keeping with our conceptual model, these core sets recognize the importance of support and relationships, attitudes of significant others and health professionals as predictors of disability in people with low back pain.

A Norwegian study in a convenience sample of 118 patients with low back pain, however, has identified gaps in the comprehensive ICF core set with respect to capturing problems of importance to patients [41]. This study compared the relationship between health problems rated by health professionals using the comprehensive ICF core set and patients' self-reported health problems identified by the Oswestry Disability Index and the World Health Organisation Disability Assessment Schedule II. Relevant domains not covered by the ICF included the subjective domain related to the impact of back pain and the feeling of being a burden to their family, while problems with sexual functions and relationship were poorly reflected in the health professionals' assessments.

Our model for the measurement of the burden of low back pain aims to comprehensively capture all of the various impacts of this condition on the individual. The model includes several domains that have not until now been considered important to measure in patients with low back pain, although they may contribute significantly to the individual's burden; for instance, loss of independence, worry about the future, negative or discriminatory actions by others, and secondary health effects, among others.

The new tool will have a wide range of potential applications for researchers, clinicians, policy-makers and insurance agencies; and for a range of purposes, including needs identification, service planning, evaluation, research and, eventually, for individual clinical assessment and monitoring. In suggesting such a range of applications, we are aware of our responsibility to consider the evidence for validity in relation to each interpretation and application $[29,30]$.

To strengthen potential generalizability, we have used both a local approach and an international approach to scope and define low back pain burden, nominal group approaches and concept mapping. The questionnaire is being developed with input from an international team of experts in the field. To facilitate comparison of the burden of back pain between countries and between studies, steps are being taken to ensure its wide applicability and cross-cultural generalizability.

In assessing health priorities, allocating resources, and evaluating the potential costs and benefits of public health interventions, governments often consider the burden of a disease and its contribution to the overall health of the population. Information obtained from a single comprehensive measure of back pain burden will greatly enhance research efforts to identify major determinants of back pain burden and population groups that are most affected and to ensure efficient allocation of resources. This information may also inform the development and evaluation of novel new interventions that could improve patient-relevant outcomes.

While the measurement model (Figure 3) does test for a single underlying latent variable, which we have called the burden of low back pain, we expect the questionnaire will be used as a multidimensional tool providing a profile of scores across the various scales. We will not be attempting to provide a scoring mechanism to gain a single overall score. In our experience it is more useful to be able to use profiles of scores to describe the needs of different patient groups and to distinguish the benefits of different types of interventions than to generate a global indicator that is at such a high level of abstraction no-one will be clear what it means. A profile of scores will also serve to highlight the critical psychosocial aspects of the burden of low back pain that have not been adequately addressed in existing tools. It is hoped that this profile of scores will support a greater clinical emphasis and increased research focus on these aspects of the burden experienced by people with back pain.

\section{Conclusions}

The present paper has described the process of developing a strong, a priori hypothesis of a measurement model for a multidimensional measurement of the burden of low back pain. The model will now be tested with a sample of approximately 600 people and may be 
refined on the basis of structural equation modeling analysis of the data. The refined tool will be retested on a separate (validation) sample of another 600 people. These are all foundational steps in a process of establishing construct validity for an expanding range of applications of the tool.

This paper has demonstrated how the application of a rigorous set of disciplines -by which grounded consultation and conceptualization processes lead to strong $a$ priori hypothesis relating to measurement - provides a firm foundation for building the evidence of validity for a wide range of potential interpretations and applications. The conceptualization process has led to a much richer and more extensive set of concepts relevant to assessing the needs of people with back pain than is captured in the outcome tools previously applied.

\section{Abbreviations}

ICF: International Classification of Functioning Disability and Health; MDS: multidimensional scaling.

\section{Acknowledgements}

The authors would like to acknowledge all participants in the concept mapping workshops for their valuable contribution to this work. RBu is supported in part by an Australian National Health and Medical Research Council Practitioner Fellowship, and $\mathrm{RHO}$ is supported in part by an Australian National Health and Medical Research Council Population Health Career Development Award.

\section{Author details}

'Monash Department of Clinical Epidemiology, Cabrini Hospital, 183 Wattletree Road, Malvern, Victoria 3144, Australia. ²Department of Epidemiology and Preventive Medicine, School of Public Health and Preventive Medicine, Monash University, The Alfred Centre, 99 Commercial Rd, Melbourne, Victoria 3004, Australia. ${ }^{3}$ Public Health Innovation, Faculty of Health, Deakin University, 221 Burwood Highway, Burwood, Victoria 3125 Australia. ${ }^{4}$ Population Health Research Unit (URESP), Research Centre of the Laval University Affiliated Hospital, Hôpital du St-Sacrement, 1050 chemin Ste-Foy, Québec, G1S 4L8, Canada. ${ }^{5}$ Department of Rehabilitation, Faculty of Medicine, Laval University, Hôpital du St-Sacrement, 1050 chemin Ste-Foy, Québec, G1S 4L8, Canada. ${ }^{6}$ Institute for Work \& Health, 81 University Avenue, Suite 800, Toronto, Ontario, M5G 2E9, Canada.

\section{Authors' contributions}

$\mathrm{RBu}$ and $\mathrm{RHO}$ conceived the study, contributed to its design and coordination, and drafted the manuscript. RBa contributed to the design of the study, performed the statistical analysis, and drafted the manuscript. GE provided input on the statistical analysis. CED and El assisted with the international expert workshop. All authors contributed to the interpretation of the findings and read and approved the final manuscript for publication.

\section{Competing interests}

The authors declare that they have no competing interests.

Received: 31 May 2011 Revised: 9 August 2011

Accepted: 20 September 2011 Published: 20 September 2011

\section{References}

1. World Health Organisation: The burden of musculoskeletal conditions at the start of the new millennium. World Health Organ Tech Rep Ser 2003, 919:-i-x, 1-218, back cover.

2. Von Korff M, Dworkin SF, Le Resche L, Kruger A: An epidemiologic comparison of pain complaints. Pain 1988, 32:173-183.

3. Hoy D, Bain C, Williams G, March L, Brooks P, Blyth F, Woolf A, Vos T, Buchbinder R: Global prevalence of low back pain. Arthritis Rheum 2011.
4. Rapoport J, Jacobs P, Bell NR, Klarenbach S: Refining the measurement of the economic burden of chronic diseases in Canada. Chronic Dis Can 2004, 25:13-21.

5. Ricci JA, Stewart WF, Chee E, Leotta C, Foley K, Hochberg MC: Back pain exacerbations and lost productive time costs in United States workers. Spine 2006, 31:3052-3060.

6. Freburger JK, Holmes GM, Agans RP, Jackman AM, Darter JD, Wallace AS, Castel LD: The rising prevalence of chronic low back pain. Arch Intern Med 2009, 169:251-258.

7. Walker B, Muller R, Grant W: Low back pain in Australian adults. Prevalence and assoicated disability. J Manipulative Physiol Ther 2004, 27:238-244.

8. Walker B, Muller R, Grant W: Low back pain in Australian adults. Health provider utilization and care seeking. J Manipulative Physiol Ther 2004, 27:327-335.

9. Dionne $C$, Dunn $K$, Croft P: Does back pain prevalence really decrease with increasing age? A systematic review. Age Ageing 2006, 35:3229-3234.

10. Walker B, Muller R, Grant W: Low back pain in Australian adults: the economic burden. Asia Pac J Public Health 2003, 15:79-87.

11. Jeffries LJ, Milanese SF, Grimmer-Somers KA: Epidemiology of adolescent spinal pain. A systematic overview of the research literature. Spine 2007, 32:2630-2637.

12. Jette A: Toward a common language for function, disability, and health. Phys Ther 2006, 86:726-734.

13. Briggs AM, Buchbinder R: Back pain: a national health priority area in Australia? Med J Aust 2009, 190:499-502.

14. Messick S: Validity. In Educational Measurement.. 3 edition. Edited by: Linn RL. New York: Macmillan; 1989:13-103.

15. Messick S: Standards-based Score Interpretation: Establishing Valid Grounds for Valid Inferences Princeton, NJ: Educational Testing Service; 1994.

16. Main C, Foster N, Buchbinder R: How important are back pain beliefs and expectations for satisfactory recovery from back pain? Best Pract Res Clin Rheumatol 2010, 24:205-218.

17. Hayden J, Dunn K, van der Windt D, Shaw W: What is the prognosis of back pain? Best Pract Res Clin Rheumatol 2010, 24:167-180.

18. Hawthorne G, Richardson J, Osborne R: The Assessment of Quality of Life (AQoL) instrument: a psychometric measure of health-related quality of life. Qual Life Res 1999, 8:209-224.

19. Batterham R, Southern D, Appleby N, Elsworth G, Fabris S, Dunt D, Young D: Construction of a GP integration model. Soc Sci Med 2002, 54:1225-1241.

20. Osborne RH, Elsworth GR, Whitfield K: The Health Education Impact Questionnaire (heiQ): an outcomes and evaluation measure for patient education and self-management interventions for people with chronic conditions. Pat Ed Counsel 2007, 66:192-201.

21. Osborne RH, Norquist JM, Elsworth GR, Busija L, Mehta V, Herring T, Gupta SB: Development and validation of the Influenza Intensity and Impact Questionnaire (FluiiQTM). Value Health 2011, 14:687-699.

22. Busija L: The avoidable burden due to arthritis in Australia. PhD thesis University of Melbourne; 2010.

23. Jordan J: Understanding the role and impact of health literacy on patient health outcomes to facilitate effective health interventions. PhD thesis University of Melbourne; 2010.

24. Ciciriello S: Development and testing of a methotrexate multimedia patient education module. PhD thesis University of Melbourne; 2011.

25. Trochim W: An introduction to concept mapping for planning and evaluation. Eval Program Plann 1989, 12:1-16.

26. van der Ven A, Delbecq A: The effectiveness of nominal, Delphi and interacting group decision making processes. Acad Management J 1974, 17:605-621.

27. Wishart D: ClustanGraphics 8. 8 edition. Edinburgh: Clustan Ltd; 2005.

28. Pedhazur E, Pedhazur Schmelkin L: Measurement, Design and Analysis: An Integrated Approach Hillsdale, NJ: Lawrence Erlbaum Associates; 1991.

29. American Educational Research Association, American Psychological Association, Joint Committee on Standards for Educational and Psychological Testing (US), National Council on Measurement in Education: Standards for Educational and Psychological Testing Washington, DC: American Educational Research Association; 1999.

30. American Psychological Association, American Educational Research Association, National Council on Measurement in Education, American Psychological Association: Standards for Educational \& Psychological Tests. 
Standards for Educational and Psychological Testing Washington, DC: American Psychological Association; 1985.

31. Cronbach L, Meehl P: Construct validity in psychological tests. Psychol Bull 1955, 52:281-302.

32. Deyo RA, Battie M, Beurskens AJ, Bombardier C, Croft P, Koes B, Malmivaara A, Roland M, Von Korff M, Waddell G: Outcome measures for low back pain research. A proposal for standardized use. Spine 1998, 23:2003-2013.

33. Bombardier C: Outcome assessments in the evaluation of treatment of spinal disorders. Summary and general recommendations. Spine 2000, 25:3100-3103.

34. Turk DC, Dworkin RH, Allen RR, Bellamy N, Brandenburg N, Carr DB, Cleeland C, Dionne R, Farrar JT, Galer BS, Hewitt DJ, Jadad AR, Katz NP, Kramer LD, Manning DC, McCormick CG, McDermott MP, McGrath P, Quessy S, Rappaport BA, Robinson JP, Royal MA, Simon L, Stauffer JW, Stein W, Tollett J, Witter J: Core outcome domains for chronic pain clinical trials: IMMPACT recommendations. Pain 2003, 106:337-345.

35. Kopec JA, Badii M, McKenna M, Lima VD, Sayre EC, Dvorak M: Computerized adaptive testing in back pain: validation of the CAT-5DQOL. Spine 2008, 33:1384-1390

36. Grotle M, Brox Jl, Vollestad NK: Functional status and disability questionnaires: what do they assess? A systematic review of backspecific outcome questionnaires. Spine 2005, 30:130-140.

37. Cieza A, Stucki G, Weigl M, Disler P, Jackel W, van der Linden S, Kostanjsek N, de Bie R: ICF core sets for low back pain. J Rehabil Med 2004, 36:69-74.

38. Weigl M, Cieza A, Cantista P, Reinhardt JD, Stucki G: Determinants of disability in chronic musculoskeletal health conditions: a literature review. Eur J Phys Rehabil Med 2008, 44:67-79.

39. Brockow T, Cieza A, Kuhlow H, Sigl T, Franke T, Harder M, Stucki G: Identifying the concepts contained in outcome measures of clinical trials on musculoskeletal disorders and chronic widespread pain using the international classification of functioning, disability and health as a reference. J Rehabil Med 2004, 30-36.

40. Ewert T, Fuessl M, Cieza A, Andersen C, Chatterji S, Kostanjsek N, Stucki G: Identification of the most common patient problems in patients with chronic conditions using the ICF checklist. J Rehabil Med 2004, 22-29.

41. Røe C, Sveen U, Bautz-Holter E: Retaining the patient perspective in the International Classification of Functioning, Disability and Health Core Set for low back pain. Patient Pref Adherence 2008, 2:337-347.

doi:10.1186/ar3468

Cite this article as: Buchbinder et al:: A validity-driven approach to the understanding of the personal and societal burden of low back pain: development of a conceptual and measurement model. Arthritis Research \& Therapy 2011 13:R152.

\section{Submit your next manuscript to BioMed Central and take full advantage of:}

- Convenient online submission

- Thorough peer review

- No space constraints or color figure charges

- Immediate publication on acceptance

- Inclusion in PubMed, CAS, Scopus and Google Scholar

- Research which is freely available for redistribution

Submit your manuscript at www.biomedcentral.com/submit
Biomed Central 